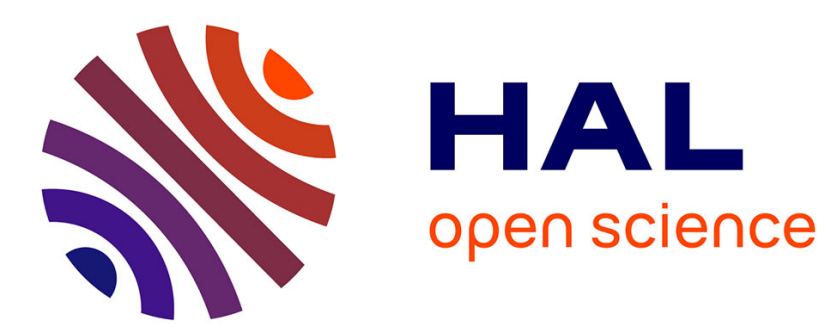

\title{
Relation between the herringbone packing and the chain behaviour in the ordered smectic phases
}

\author{
J. Doucet
}

\section{To cite this version:}

J. Doucet. Relation between the herringbone packing and the chain behaviour in the ordered smectic phases. Journal de Physique Lettres, 1979, 40 (8), pp.185-187. 10.1051/jphyslet:01979004008018500 . jpa-00231603

\section{HAL Id: jpa-00231603 https://hal.science/jpa-00231603}

Submitted on 1 Jan 1979

HAL is a multi-disciplinary open access archive for the deposit and dissemination of scientific research documents, whether they are published or not. The documents may come from teaching and research institutions in France or abroad, or from public or private research centers.
L'archive ouverte pluridisciplinaire HAL, est destinée au dépôt et à la diffusion de documents scientifiques de niveau recherche, publiés ou non, émanant des établissements d'enseignement et de recherche français ou étrangers, des laboratoires publics ou privés. 


\title{
Relation between the herringbone packing and the chain behaviour in the ordered smectic phases
}

\author{
J. Doucet \\ Laboratoire de Physique des Solides (*), Université Paris-Sud, \\ Bâtiment 510, 91405 Orsay, France
}

(Reçu le 18 janvier 1979, accepté le 23 février 1979)

Résumé. - A partir de considérations d'encombrement stérique, nous montrons que l'empilement en chevrons, qui est caractéristique des phases smectiques ordonnées, est déterminé par des facteurs géométriques, contrairement aux théories classiques qui sont basées sur l'interaction dipolaire.

\begin{abstract}
By simple steric considerations, we intend to show that the herringbone packing, which is characteristic of the ordered smectic phases, is governed by geometrical factors, contrary to the usually admitted theories which are based on dipolar interactions.
\end{abstract}

It appears that molecules giving rise to mesomorphic phases are generally formed by a rigid aromatic central part at the extremities of which are tied flexible terminal chains of carbon atoms (alkyl or alkoxy).

Various experiments have shown that the crystal $\rightarrow$ smectic phase transition is directly connected with the melting of the chains (e.g. dilatometry [1], E.P.R. [2], neutron scattering [3]). A more precise result obtained by N.M.R. experiments performed on selectively deuterated molecules [4], reveal that no large differences can be observed in the chain behaviour between the nematic and the ordered smectic phases (i.e. smectic phases with periodic order within layers). Also the atomic disorder increases when moving away from the central part of the molecules along the chain.

Studies of the four main structural kinds of ordered smectic phases (smectic B, E, G, H) indicate that the packing between neighbouring molecules within the layers is nothing but the so-called herringbone packing (Fig. 1) irrespective of the compound. The centres of mass of the molecules are arranged at the nodes of a periodic rectangular lattice, the orientation of the molecules around their long axes being ensured by a glide-mirror placed in such a way that the molecular sections parallel to the smectic layers are arranged in a herringbone array.

According to the type of the ordered smectic phase selected, this order is either effective over

(*) Laboratoire associé au C.N.R.S.

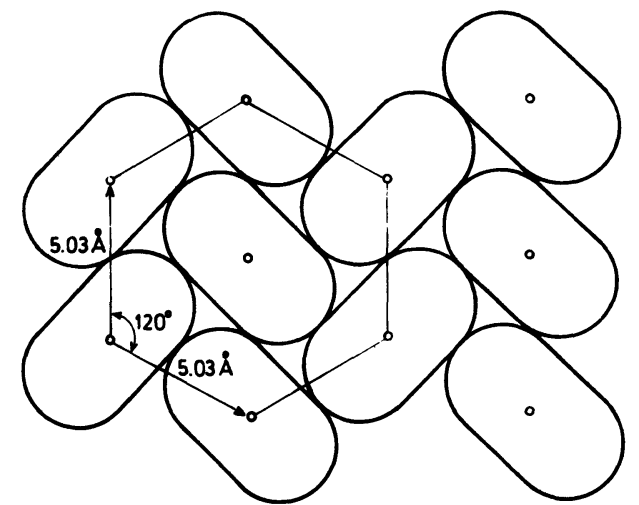

Fig. 1. - Schematic representation of the herringbone packing. Each oval corresponds to the section of the central part of the molecules in a plane parallel to the smectic layers. The centres of mass of the molecules are arranged at the nodes of a periodic lattice which can be described either by a rectangular centred cell or by a pseudo-hexagonal (or hexagonal) cell.

large distances or is locally retained because of the rotation of the molecules around their long axes. In the latter case, this order is only effective within small domains (typical size $10 \AA$ to $30 \AA$ ) oriented in three directions and thus displays 12 orientations of the molecules around their long axes [5], [6], i.e. two orientations in each rectangular cell, multiplied by three orientations of these rectangular cells and by two if we take into account the two-fold reorientations through an angle $\pi$.

These two observations of the behaviour of the terminal chains and of the rigid central part of the molecules lead us to pose the question : is there any 
relationship between the herringbone packing and the melting of the chains in the ordered smectic phases? We intend to show, from simple steric considerations, how and why these two observations may be reconciled.

We shall try to find out the origin of the herringbone packing, and what are the predominant factors determining this packing ?

A molecular theory of the ordered smectic phases has been proposed [7] based mainly on the dipoledipole interaction. Despite some interesting predictions, this theory cannot be correct since the description of the various smectic phases is not in agreement with the experimental observations of $\mathrm{X}$-ray scattering. The major disagreement concerns the molecular packing within the layers : only two of the four types of ordered smectic phases are described as having the herringbone packing. In this theory, the importance of the dipolar interaction is over-estimated with respect to the geometrical and packing factors. Indeed, experiments have already shown for the nematic phase that the predominant factors determining the mesophase stability are geometric and polarity has little effect [8]. Accordingly a reinforced and more significant conclusion would be expected for smectic phases as such phases are much more ordered than the nematic phase.

According to A. I. Kitaigorosdkii [9], an organic crystal can be considered as formed by the packing of well defined shaped molecules, the most compact packing leading to a minimum free energy. The other chemical or physical factors, such as the nature of the atoms, the dipolar moments or the polarizabilities play a less important role.

We shall give a tentative explanation of how a herringbone packing can be deduced from such considerations. Firstly, we assimilate the molecular section parallel to the smectic layers to that of a benzene ring since the central part of the molecules is usually formed by para-bi-substituted benzene rings. We can easily determine the dimensions of this section from the Van der Waals radius of the carbon $(1.80 \AA)$ and $H(1.17 \AA)$ atoms and from the $\mathrm{C}-\mathrm{C}(1.39 \AA)$ and $\mathrm{C}-\mathrm{H}(1.05 \AA)$ bond lengths. The minimum distance between two benzene rings belonging to two adjacent molecules in the same layer is equal to about $6.25 \AA$, and the thickness of a benzene ring is about $3.5 \AA$ [9]. To simplify, we shall consider only the rectangular envelope of this section, the side lengths of which are respectively 6.25 and $3.5 \AA$. The three easiest ways to juxtapose these rectangles into a periodic arrangement so that they entirely cover the surface of the plane are drawn in figure 2 . These three packings are the most compact and hence are equally probable in a first approximation. In order to distinguish between these arrays, we have now to take into account the terminal chains. We already mentioned that in the smectic phases, the chains are in a state usually called melting. In (b)
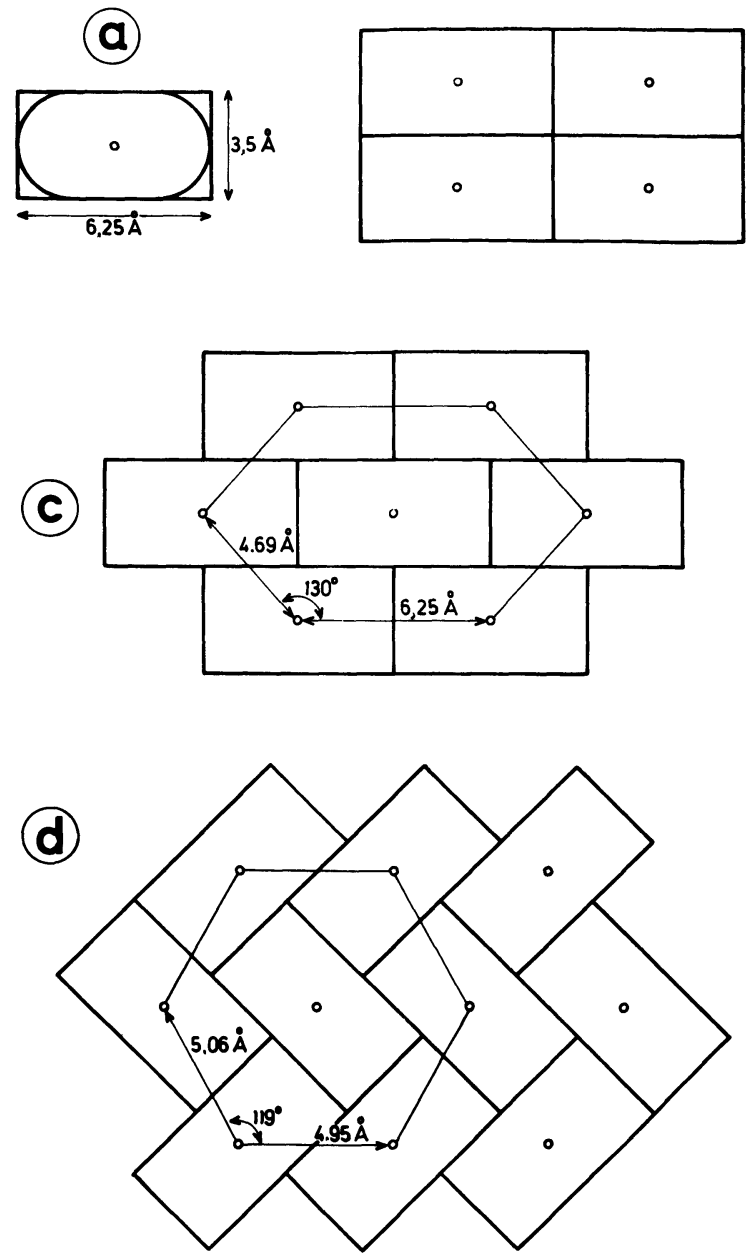

Fig. 2. - a) Rectangular envelope of the molecular section. $b), c), d)$ The three easiest periodic arrangements of the envelopes defined in $a$ ). The centres of mass of the molecules in the packing $d$ ) (herringbone packing) are distributed at the nodes of a nearly hexagonal lattice; thus, it is also the most suitable for the packing of the terminal chains.

this state, all the chains with a similar degree of disorder may be considered as being localized within cylinders of the same diameter. Thus the chains have a tendency to pack into an hexagonal array and figure 2 shows that the packing which fits best this condition is of the herringbone type since it corresponds to a nearly regular hexagonal array of the mass centres of the molecules (side length $4.95 \AA$ and $5.06 \AA$, angle $110^{\circ}$ ). It is noteworthy that the two-dimensional lattice becomes regular if we choose a molecular section with rounded corners (Fig. 1) i.e. its side length is $5.03 \AA$ in agreement with the values obtained for the smectic $B$ phases that usually range from 4.90 to $5.10 \AA$ [10], [11]. For phases with tilted molecules, this value should be compared with that of the lattice projections on a plane perpendicular to the long molecular axes.

This explanation may appear schematic since most of the molecules have more than one benzene ring. 
Usually, in the crystalline phases of mesogenic compounds, these rings make fairly large angles with respect to each other. In fact such a remark should not change our conclusion if we realize that in the smectic phases the thermal motion is very important, the benzene rings undergoing large amplitude oscillations.

Under such conditions, it is probably safe to assume that the conformation of the central part of the molecule is in average not far from the coplanar conformation, which leads to the herringbone packing.

From these packing considerations, we can also deduce some characteristics of the melting state of the chains. The area per section of the chain is equal to about $21 \AA^{2}$ to $22 \AA^{2}$ in the ordered smectic phases (values similar to those measured in lipids [12]), whereas it ranges from $18 \AA^{2}$ to $19 \AA^{2}$ in the crystalline phases of paraffins (t-t-t conformation) [13]. The comparison between these values implies that, in spite of the great thermal motion, the melting state of the terminal chains in the ordered smectic phases is not a liquid state, but a state in which the chains keep a conformation not far from the linear conformation.

One problem with this explanation of the herringbone packing is that the crystalline phases producing ordered smectic phases on melting, are not systematically characterized by a herringbone packing (for instance, TBBA [14]). In fact, if we assume that the molecules adopt the same configuration in the two different phases and that the packing depends mainly on geometrical factors, we can conclude that the packing must be identical. But this conclusion is not so straightforward since one must take into account the very big difference between the thermal motion of the crystalline and the ordered smectic phases. In the ordered smectic phases, the thermal motion is large as the molecules undergo reorientational jumps around their long axes or large amplitude oscillations with respect to their mean orientations [15]. Thus, the intermolecular interactions are weakened, and this allows the molecules to take up their external shape or envelope, the nature of the atoms being unimportant. Therefore, the approximation used above to define the molecular cross section (Fig. 2) is justified. However, in the crystalline phase, the thermal motion is much less important than in the ordered smectic phases and the approximation of the envelope describing the molecule is too rough : all the intermolecular interactions must be taken into account, and thus the resulting packing is not necessarily of the herringbone type. The compactness of the packing also eliminates the possibility of free molecular rotations around their long axes in the smectic $B$ and $G$ phases. These rotations to be achieved probably require longitudinal translational motion of the molecules correlated in the directions of the long molecular axes [16].
The ideas proposed here are difficult to verify with accuracy. Nevertheless an explanation relevant to the herringbone packing that would confirm our proposal has been formulated by J. Billard [17]. The argument proceeds as follows : if it is assumed that the herringbone array corresponds to the most compact packing of the molecules, whose sections of the central part can be roughly assimilated to the section of a benzene ring, then molecules with a different section or shape should not adopt the herringbone packing. This has been checked for all the compounds with a naphtalenic central part and none of them exhibit an ordered smectic phase. This appears to be a convincing argument in favour of our interpretation.

In conclusion, the herringbone packing observed in the ordered smectic phases corresponds to the most compact array compatible with both the arrangement of the central part and the terminal chains of the molecules. Contrary to current thinking, the factors controlling this packing are geometrical and other factors such as the dipolar moment play only a minor part.

Acknowledgments. -- I wish to thank Prof. M. Lambert and Mrs A. M. Levelut for their helpful commentaries about the text and Mrs M. C. Comes for revising the english of the manuscript.

\section{References}

[1] Guillon, D. and Skoulios, A., C. R. Hebd. Séan. Acad. Sci. Paris 278 série C (1974) 389.

[2] Dvolaitsky, M., Poldy, F. and Taupin, C., Phys. Lett. 45A (1973) 454.

[3] Hervet, H., Volino, F., Dianoux, A. J. and Lechner, R. E. J. Physique Lett. 35 (1974) L-151.

[4] Deloche, B. and Charvolin, J., J. Physique 37 (1976) 1497.

[5] Doucet, J., Levelut, A. M. and Lambert, M., Phys. Rev. Lett. 32 (1974) 301.

[6] Doucet, J., Levelut, A. M. and Lambert, M., Ann. Phys. 3 (1978) 157.

[7] a) MeYer, R. J., Phys. Rev. A 12 (1975) 1066.

b) Meyer, R. J. and McMillan, W. L., Phys. Rev. A 9 (1974) 899.

[8] a) Dewar, M. J. S. and Riddle, R. M., J. Am. Chem. Soc. $97: 23$ (1975) 6658.

b) Dewar, M. J. S. and Griffin, A. C., J. Am. Chem. Soc. $97: 23$ (1975) 6662.

[9] KitaigorodsKiI, A. I., Molecular crystals and molecules (New York, Academic Press) 1973.

[10] Doucet, J. and Levelut, A. M., J. Physique 38 (1977) 1163.

[11] De Vries, A., Pramana, Suppl. no 1 (1975) 93.

[12] Tardieu, A. and Luzzati, V., J. Mol. Biol. 75 (1973) 711.

[13] Müller, A., Proc. R. Soc. A 127 (1932) 417.

[14] a) Doucet, J., Mornon, J. P., Chevalier, R. and LifCHITZ, A., Acta Crystallogr. B 33 (1977) 1701.

b) Doucet, J., Levelut, A. M. and Lambert, M., Acta Crystallogr. B 33 (1977) 1710.

[15] Volino, F., Dianoux, A. J. and Hervet, H., J. Physique Colloq. 37 (1976) C 3-55.

[16] Levelut, A. M. and Lambert, M., C. R. Hebd. Séan. Acad. Sci. Paris 272B (1972) 1018.

[17] BillaRd, J., Private communication. 